\title{
Exploring quantitative relationship through area conservation activity
}

\author{
Puspita Sari1 ${ }^{1 *}$ (D) $\mathrm{Ng}$ Swee Fong ${ }^{2}$ \\ ${ }^{1}$ Mathematics Education, Universitas Negeri Jakarta, Jakarta, Indonesia \\ 2Mathematics and Mathematics Education, National Institute of Education, Nanyang Technological University, Singapore \\ *Correspondence: puspitasari@unj.ac.id
}

Received: 4 January 2022 | Revised: 28 January 2022 | Accepted: 6 February 2022 | Published Online: 11 February 2022

(C) The Author(s) 2022

\begin{abstract}
Algebra as a study of quantitative relationship is one of four conceptions of school algebra which serves as a foundation for the concept of function. However, there is still a lack of attention to this particular relationship, especially in early algebraic reasoning. This study aims to investigate how the aspect of quantitative relationship in early algebra can be explored through area conservation activities. Understanding area conservation is said to be fundamental in developing the concept of area measurement. In this study, a ten-year old pupil was observed during her involvement while comparing area of two polygons that can be decomposed into equivalent triangles. Data for this study include the pupil's written artefacts, and video recordings of the activities and interviews. Findings from this study show that the area conservation activity has the potential to build the notion of quantitative relationships in early algebra. The quantitative relationship between the unit of measurement and the result of measurement of a shape can also be explored, that is, the smaller the unit of measurement, the larger the result of measurement. Hence, this study can provide a groundwork for further studies in the relation between quantitative relationship in algebra and area conservation in geometry at the elementary school level.
\end{abstract}

Keywords: Area Conservation, Area Measurement, Early Algebra, Quantitative Relationship

How to Cite: Sari, P., \& Ng, S.F. (2022). Exploring quantitative relationship through area conservation activity. Journal on Mathematics Education, 13(1), 31-50. http://doi.org/10.22342/jme.v13i1.pp31-50

Students' difficulties in learning algebra have drawn a lot of attention to the study of early algebraic thinking as an attempt to bridge the gap between arithmetic in elementary school and algebra in secondary school (Amerom, 2003; Banerjee \& Subramaniam, 2012; Blanton et al., 2019; Davydov, 1962; Freudenthal, 1974; Kieran \& Ng, 2018; Kieran et al., 2016; Peck \& Jenks, 1988). Early algebraic thinking involves ways of thinking or reasoning which include analyzing relationships among quantities, noticing structure, studying change, generalizing, problem solving, modeling, justifying, proving, and predicting (Kaput, 2008; Kieran, 2004). Kaput (2008) posited that all these forms of reasoning infused the central notions of generalization and the meaningful use of symbols. Further research went on to show that, early algebraic thinking could still occur even when the letter-symbol is not utilized in pupils' reasoning. For example, Kieran et al. (2016) identified research on the development of early algebraic thinking in the past two decades that have mainly focused on the process of generalizing, being related to numeric and geometric pattern generalization.

In contrast to teaching algebra as generalized arithmetic, Davydov (1962; 1975) used letter symbols as the point of departure to explore properties of real numbers and quantitative relationships in 
algebraic thinking since the first grade of elementary school. Although this was considered as a radical approach in the early algebraic thinking, Freudenthal $(1974 ; 1978)$ confirmed that by using letter symbols, pupils were compelled to fix their attentions on the relations between magnitudes and on their variability, and thus this approach offers many advantages than the arithmetical approach to algebra. Correspond to that, exploring quantitative relationships in terms of magnitudes of area can be implemented in an area conservation activity. In the area conservation activity, pupils can compare area of different shapes by exploring the geometrical shapes and the partial units of the shapes, rather than using formula to calculate and compare the area. However, Lehrer (2003) and Stephan and Clements (2004) identified that pupils have difficulties in perceiving the area conservation concept, that is, the area of a shape is conserved whenever its parts are decomposed and recomposed into another shape.

This study investigated how quantitative relationship in early algebraic thinking can be explored through area conservation activities. Specifically, this study explored how a pupil built the concept of quantitative relationships and the concept of area conservation while engaging in the activities of comparing magnitudes in terms of area. The activities consisted of comparing area of two or more polygons that can be decomposed into several equivalent triangles (e.g., right, or isosceles triangles). Findings of this study could provide insight and motivation for further studies in investigating the relationship between quantitative relationship in early algebra and area conservation in geometry at the elementary level.

\section{Quantitative Relationship in Early Algebra}

Algebra as the study of relationships among quantities deals with describing relationships among variables, such as "what happens to $1 / x$ as $x$ gets larger?", where the variable $x$ does not signify a specific unknown, instead as quantities that vary (Usiskin, 1988). Quantitative relationships also appear in the content categories of PISA ${ }^{1}$ framework, where "the aspect of quantity includes the quantification of attributes of objects, relationships, situations and entities in the world, understanding various representations of those quantifications and judging interpretations and arguments based on quantity" (OECD, 2019, p. 85). Hence, the aspect of relationships of attributes of objects can be seen as a crucial part in making interpretations and providing arguments. Principles and Standards for School Mathematics (NCTM, 2000) identifies quantitative relationships as parts of algebra standards from Pre-K to grade twelve, for example: modeling situations that involve addition and subtraction of whole numbers by using objects, pictures, and symbols, in grade Pre-K to grade two; and making a general statement about how one variable is related to another variable in grade three to five (NCTM, 2000). The study of quantitative relationships in the early grades could serve as a foundation to the concept of functions and graphical representations (Usiskin, 1988; NCTM, 2000; OECD, 2019).

Rather than just performing standard calculations in finding numerical answers, Davydov's (1962; 1975) groundbreaking Russian curriculum highlighted the need to promote quantitative relationships with parameters, such as length, volume, area, time interval, and weight, focusing on relationships such as "equal", "more than", and "less than". Letters were used to specify such relationships and numbers was only one aspect of the relationships. For example, given two ribbons, one longer than the other, the relationship could be expressed as $A>B$. This comparative relationship could be expressed as $5>3$, numerically. Therefore, letter symbols were introduced as a means of exploring relations between magnitudes (quantities), beginning with the first grade of primary school. The American Measure Up (MU)

\footnotetext{
${ }^{1}$ PISA (Programme for International Student Assessment) measures students' literacy in reading, mathematics, and science, for students aged 15.
} 
project by Dougherty (2008) supported Davydov's claims: the exploration of quantitative reasoning offered evidence that young children were able to build meaningful, sophisticated and complex mathematics. Moreover, a recent study by Freiman and Fellus (2021) suggested that Davydov's approach could potentially bridge the gap between arithmetic and algebraic thinking by allowing pupils to build on various semiotic systems, including letters, in exploring relationships between quantities.

\section{The Concept of Area Conservation in Area Measurement}

There are at least four basic concepts involved in learning area and area measurement concepts, i.e., partitioning, unit iteration, conservation, and structuring an array (Lehrer, 2003; Stephan \& Clements, 2004). In addition, Outhred and Mitchelmore (2000) identified four basic principles in developing pupils' intuitive understanding of area measurement: complete covering, spatial structure, size relations, and multiplicative structure. As with complete covering, pupils should experience covering a region with a fixed unit without overlaps or gaps. Furthermore, Piaget et al. (1960) explained in area measurement, the concept of conservation assumes that the partial units of it are conserved and can be composed in many ways to form invariant wholes. Specifically, whenever the partial units are rearranged, the total area stays the same. Piaget and his colleagues also emphasized that concepts of compensation, part-whole relationship, reversibility, and transitivity are fundamental to the concept of area conservation. In Figure 1 (i), $A B C D$ is a square of length $a$ unit and $E F G H$ is another square within $A B C D$. Area of square $A B C D$ is $a \mathrm{x} a$, and that of $E F G H$ is $\frac{a \times a}{2}$. The part-whole relationship implies that the square EFGH can be perceived as a part of the square $A B C D$, and the square $E F G H$ can be decomposed into two triangles $E F G$ and $E G H$. When the triangle EFG is rearranged to form rectangle EGCD in Figure 1 (ii), the area of the recomposed figure is that of the rectangle $\frac{1}{2} a \times a$. Hence, area of triangles $E D H$ and $G C H$ compensate the area of triangle EFG in EFGH. Transitivity in making inferences means that if " $A=B$ and $B=C$, then $A=C$ ", while reversibility in area conservation means that a shape that has been rearranged into a different shape can be returned to the original shape.

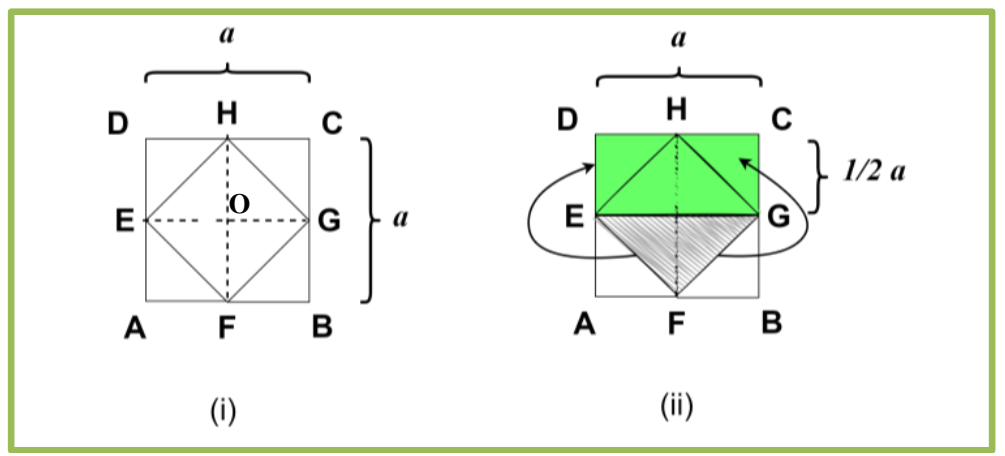

Figure 1. area conservation by compensating the partial units of the area.

Introducing rules and procedures prematurely without sufficient understanding could cause pupils' difficulties in solving area measurement problems (Kamii \& Kysh, 2006; Kospentaris et al., 2011). In particular, pupils have difficulties making sense of the concept of area conservation. Kordaki (2003) and Kospentaris et al. (2011) emphasized that the understanding of area conservation should precede the introduction of formulae and procedures in the area measurement concept. However, teaching instructions in classrooms often neglect the concept of conservation, and tend to emphasize the use of formula to find the area of a given shape (Stephan \& Clements, 2004). Figure 2 illustrates how pupils 
succeeded to find the area of a parallelogram (Figure $A$ ) by using the formula "base $\mathrm{x}$ height" but failed to find the area of the parallelogram (Figure $B$ ) that was slightly modified. In this 'area of the parallelogram' problem, Wertheimer (1945) emphasized the importance of seeing the inner structural relation of the figure, instead of merely following the teacher's procedural instruction to the problem. In this case, pupils' limited understanding of area measurement was what defined by Skemp (1976) as evidence to instrumental understanding: pupils know how to apply the appropriate rule to the area problem without knowing why the rule works. Instrumental understanding can be a hurdle as pupils may find it challenging to apply the procedure to slightly modified problems.

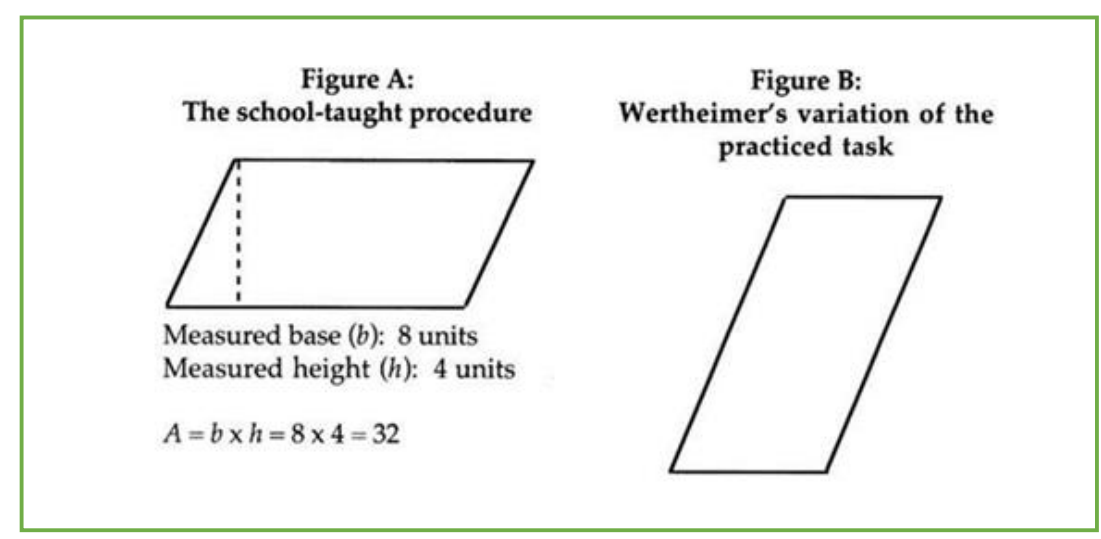

Figure 2. An example of pupils' common mistakes in area measurement (source: The Wertheimer's problem in Baroody (2003))

\section{METHODS}

The aim of this one-on-one (the teacher-researcher and pupils) teaching experiment study (Cobb et al., 2003; Steffe \& Thompson, 2000), was to study the process by which a small number of pupils develop their understanding of particular mathematical concepts while engaging in a series of designed activities. The highly-interventionist nature of the methodology allows the researchers to drawn on prior research in designing and implementing an innovation which is not typical of teaching practices in general (Cobb et al., 2003). The following sections explain the participant, procedures, and the sequence of activities for this study. Due to the covid-19 restriction during the data collection, there was only one pupil participating in the present study.

\section{The Participant}

The participant was a 10-year-old 4th grade elementary school pupil in one of private schools in Jakarta, Indonesia. The school implemented the 2013 Indonesian national curriculum like many other public schools in Indonesia. The pupil was chosen based on the proximity to one of the researchers. At the time of the study, the pupil was in the beginning of her second semester of the fourth grade. She was able to apply formulae in calculating areas of two-dimensional shapes, such as triangles, squares, and rectangles, which had been taught just before this study was carried out. Although she was one of the high-performing pupils in her school, her mathematics ability was still limited to solving routine mathematics problems. Thus, the pupil could represent typical students who can apply routine procedures, but still have difficulties in solving challenging or non-routine problems. Furthermore, she had no experience in area conservation activities and the use of letters to express algebraic relationships including quantitative relationships. Prior to this study, we have obtained consent from the parent and the 
pupil to participate in this study. Henceforth, the letter $P$ is used to identify the pupil.

\section{Procedures}

In this study, two 80-minute sessions were conducted outside the school curriculum time. One of the researchers acted as the teacher in delivering the activities as the aim and the content of the mathematics activities were different from common teaching practices in the school. The four activities in this study were presented in such order so that $P$ could build the concept of area conservation and quantitative relationships by comparing area of different shapes without knowing the exact measurements of the shapes, such as length, base, or height. Activities 1 and 2 were presented in the first session, and Activities 3 and 4 , in the second session. The two sessions were videotaped by placing a video recorder on a tripod at the back of the study room. The contents of the videos were analyzed to identify critical moments of P's engagement with the activities. Data also included P's written works and interviews during the activities. Relevant sections of the interviews were transcribed and coded. The coded focused specifically on P's interaction with the concepts of compensation, part-whole relationship, reversibility, and transitivity.

\section{The Sequence of Activities}

Activities 1-3 consist of comparing area of two-dimensional shapes that can be decomposed into several equivalent triangles, and Activity 4 involves expressing the area of different shapes using letter-symbols $(A$ and $B)$ that signify the unit of measurement. The activities focused on exploring the area conservation concept and quantitative relationships in comparing magnitudes of area, such as "equal", "smaller than", and "larger than". The sequence of activities has dual objectives, (i) to promote the pupil's thinking in developing the concept of quantitative relationships in early algebra; and (ii) to build the pupil's understanding of area conservation which is fundamental for the concept of area measurement. The learning objectives were formulated in alignment with the NCTM (2000) Standards in algebra and geometry strands for grade 3-5, that is: (1) use mathematical models to represent and understand quantitative relationships (algebra standard), and (2) develop mathematical argument about geometric properties and relationship by investigating the shapes with equal area and exploring how geometry and measurement related (geometry standard). Although these goals were not clearly specified in the Indonesian curriculum, $\mathrm{K} 13$, but there are clear connections with the intent of the Indonesian curriculum and the NCTM Standards.

The purpose of Activity 1 and 2 was to examine P's reasoning in developing the meaning of area conservation where the four concepts of compensation, part-whole relationship, reversibility, and transitivity (Piaget et al., 1960) play a part. Activity 1 consists of tasks (i) - (iii) (Figure 3), Activity 2 consists of one task (Figure 4), Activity 3 consists of tasks (i) - (iv) (Figure 5), and Activity 4 consists of tasks (i) - (iv) (Figure 6). The difference between Activity 1 and 2 was in the use of the concrete material. In Activity 1, a piece of origami paper as the concrete material was used as a tool to help P modeled the problem, whereas in Activity 2, the concrete material was no longer in use. $P$ was encouraged to perceive the grid on the paper as the representation of the concrete material. The purpose of Activity 3 was to further investigate how $P$ reasoned in terms of the four concepts while developing the concept of quantitative relationship such as "equal", "smaller than", and "larger than". Activity 4 was intended to see how $P$ reasoned algebraically in terms of letter-symbols representing different units of measurement. Instead of quantifying the size of the unit square as the measurement unit, this activity used labels $A$ and $B$ to represent the area covered by the unit square and the unit triangle (half of the square) to find the area of various shapes. Activity 4 allowed $P$ to explore the quantitative relationship: the smaller the 
measurement unit, the bigger the result of the measurement. Possible guiding questions were also provided to anticipate the pupil's difficulties while engaging in the activity.

\section{Activity 1. Area Conservation by Covering}

- Learning objectives: $P$ will be able to compare area of different shapes without using formulae, that is by applying the concepts of compensation, part-whole relationship, reversibility, or transitivity.

- Tools: origami paper, scissor, whiteboard.

- Activity: Exploring area conservation by the 'cut and paste' strategy using origami paper.

- Guiding Questions: "Can you cut and paste the square to the shape? "How many squares do you need to cover the region inside this shape?" "If you move this shape, do you think the area will change?"

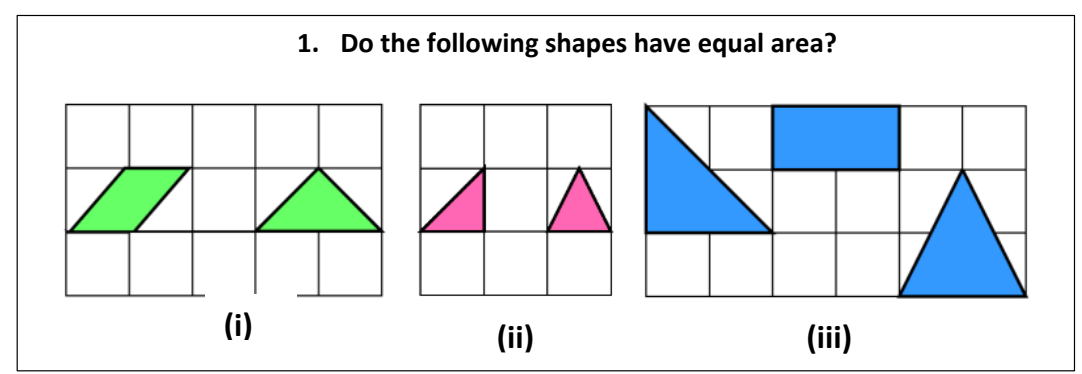

Figure 3. Area Conservation by Covering

Activity 2. Area Conservation by Tessellation

- Learning objectives: $P$ will be able to compare area of different shapes without using formulae, that is by applying the concepts of compensation, part-whole relationship, reversibility, or transitivity

- Tools: a worksheet with grids

- Activity: Exploring area conservation by the 'cut and paste' strategy

- Guiding Questions:

"Do you think these shapes cover the same area?"

"Do these shapes need the same number of squares to cover the area?"

"Does this shape need more squares than the other one? Why?"

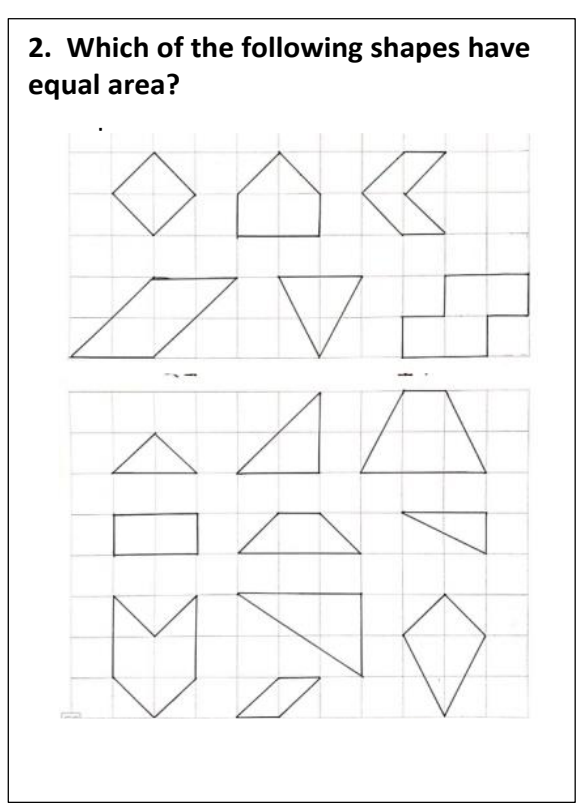

Figure 4. Area Conservation by Tessellation

\section{Activity 3. Area Comparison}

- Learning objectives: $\mathrm{P}$ will be able to determine the equality or inequality of area between two different shapes without using formulae.

- Tools: a worksheet with grids

- Activity: Comparing magnitudes of areas ("equal", "less than", "more than"). 
- Guiding Questions: "Is there any difference between the triangle in task (ii) and task (iii)? "Do you think these shapes cover the same area?"

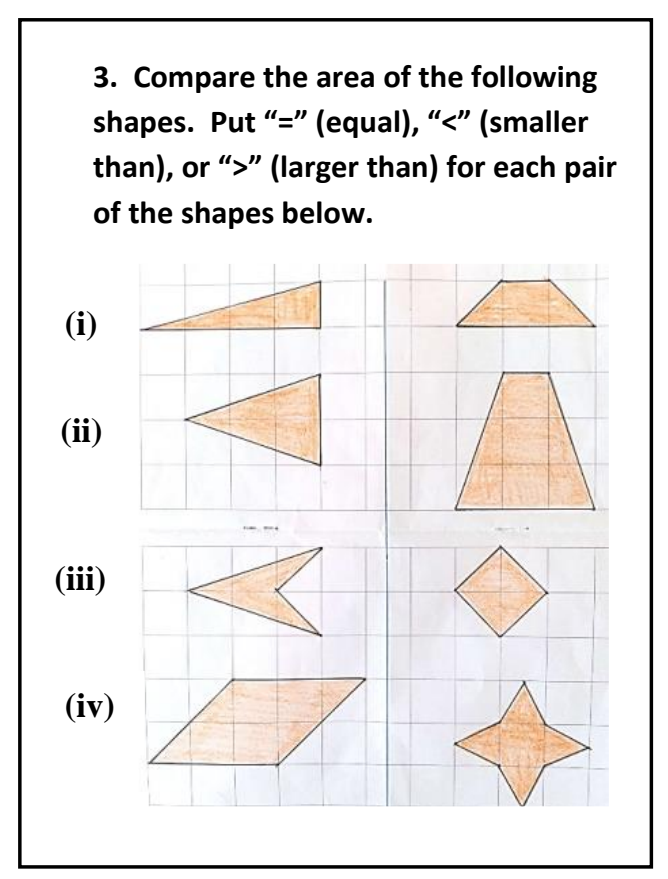

Figure 5. Area Comparison
4. Determine the area of each shape in terms of $A$ and $B$

(i)

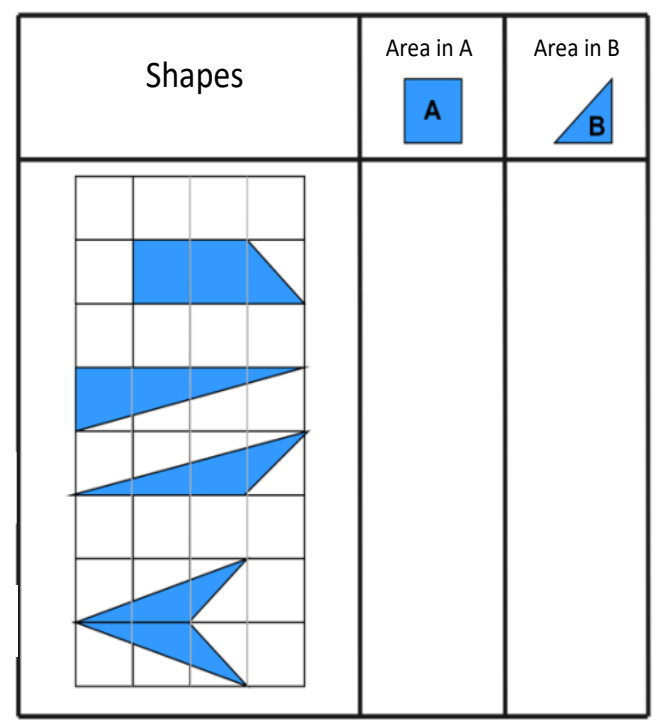

Figure 6. Letter-Symbolic Comparison

Activity 4. Letter-Symbolic Comparison

- Learning objectives: $\mathrm{P}$ will be able to reason algebraically (in terms of letter-symbols) in comparing magnitudes of area.

- Tools: a worksheet with grids.

- Activity: Using letters to represent areas (in terms of different units)

- Guiding Questions: "Can you see the relation between this triangular shape and this rectangular shape?"

\section{RESULTS AND DISCUSSION}

Grids were drawn on the whiteboard with the measurement of the unit square the same as the measurement of the origami paper used, $12 \times 12 \mathrm{~cm}$. During the first activity, $P$ could use the origami paper as a tool to cover the given shapes (Figure 3) by first cutting the paper diagonally into two equivalent triangles. In this manner, $\mathrm{P}$ could shift, rotate, or turn the paper to cover or form the shapes. Once $P$ was confident in mentally shifting, rotating, or turning the pieces of origami, $P$ moved on to solving problems in a checkered paper exercise book for the next activities. The following sections describe P's responses in each activity followed by a discussion of the present study.

\section{Activity 1. Area Conservation by Covering}

This activity was designed to develop the idea of area conservation. A square unit was drawn on the whiteboard and a letter ' $A$ ' was used to denote the area of the square unit. We agreed to use letter $A$ to signify the area of the square unit, since we did not know the measurement of the square, and thus we could not quantify the area. Next, a parallelogram and a triangle were drawn on the whiteboard (see 
Figure 3 (i)), and the question was given: "Does the area of the parallelogram equal to the area of the triangle?". Because P could not answer the question, a piece of square origami paper was given to model the problem. After $P$ folded the square paper along its diagonal and cut the paper diagonally, $P$ could see that the square paper can be decomposed into two equivalent isosceles right triangles.

This question "Can you see this triangular shape in this parallelogram?" followed the successful folding phase. By shifting and turning the pieces of the two equivalent triangles (half of the square paper), $P$ gradually realized that the two equivalent triangles covered the parallelogram shape without overlaps or gaps. The grid pattern on the whiteboard helped $P$ to see the structure of the shape easily, and the origami paper allowed her to rotate the triangular shapes freely so that both pieces fitted perfectly to form the parallelogram. The following questions were found to be helpful in fostering P's thinking in developing the concept of area conservation during the discussion:

"Can you see this triangular shape in this parallelogram?"

"Does a piece of origami paper can cover all the surface?"

"How do you know that the area of the parallelogram equals the area of the triangle?"

"If you rearrange the triangles so that the parallelogram become a square, does the area change?"

Furthermore, by asking $P$ to rearrange the shapes, the idea of reversibility became apparent when $P$ could reverse the arrangement of the parallelogram and the isosceles triangle into the initial square (Figure 7). The idea of transitivity was also evident when $\mathrm{P}$ said: "the area of the square equals to the area of parallelogram and the triangle, so the area of the parallelogram equals to the area of the triangle". In other words, if " $B=A$ and $A=C$, then $B=C$ ".

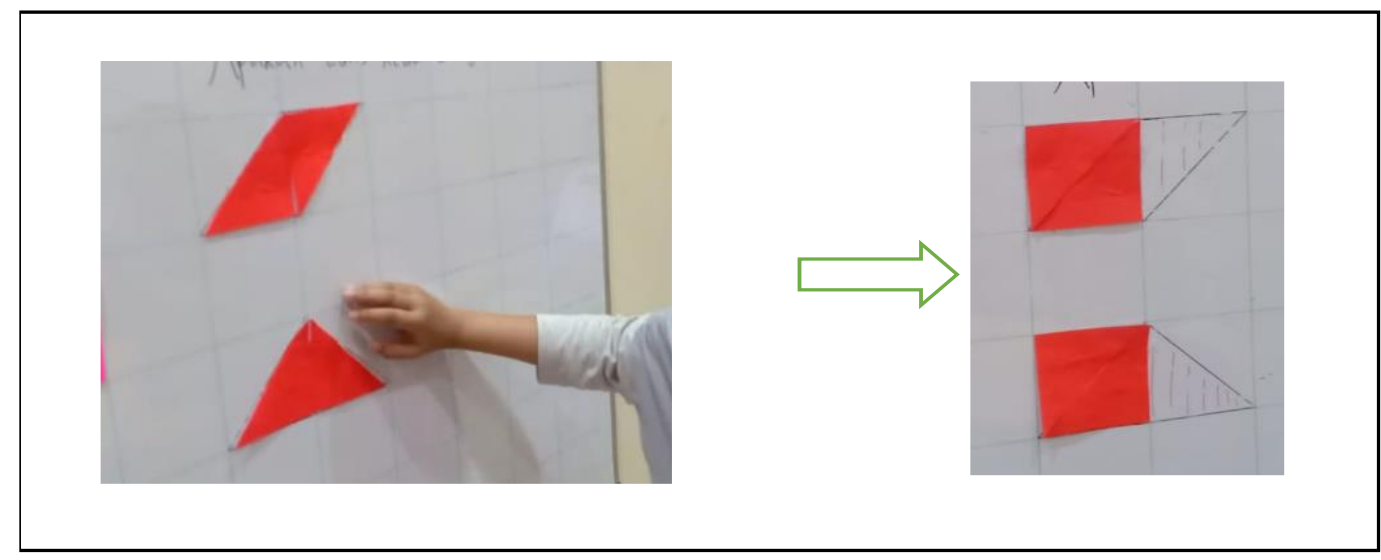

Figure 7. Concepts of reversibility and transitivity in Activity 1, task (i)

In Activity 1, task (ii) was more challenging than task (i) (Figure 3 (i) and 3 (ii)). As conjectured before, $\mathrm{P}$ had difficulties in comparing area of the two triangles in task (ii). This problem was intended to bring about the idea of part-whole relationship and compensation. P explained that: "the area of the two triangles is different, because the first one is half of the square, while the second one is an isosceles triangle" (Figure 3 (ii)). This suggests that $P$ gave an argument based on the shape of the triangle. Although P could see the first triangle (the right isosceles triangle) as half of the square, it was not the case for the second triangle (the isosceles triangle). $P$ could see the part-whole relationship between the first triangle and the initial square, but $P$ could not see that the second triangle was made up of two smaller right triangles that are parts of the initial square (Figure 8). 


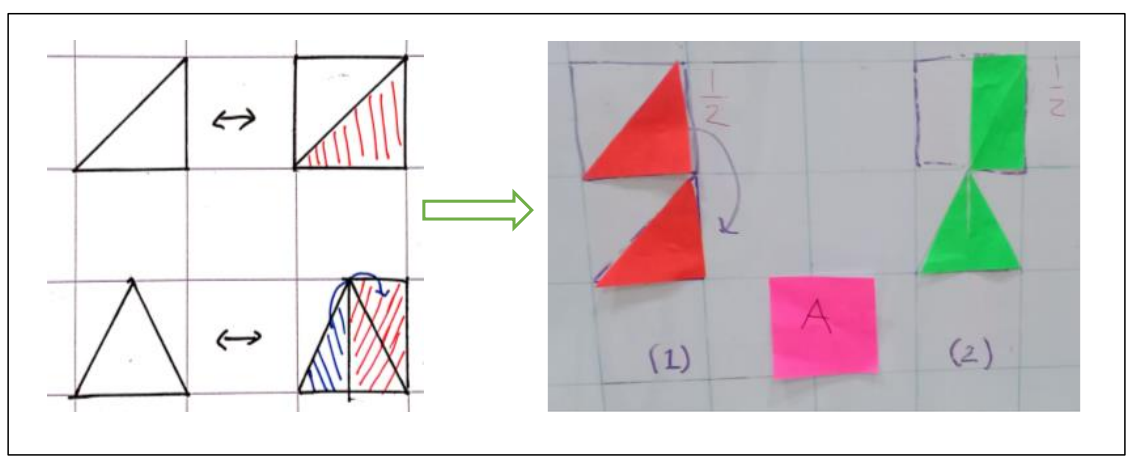

Figure 8. Concepts of part-whole relationship and compensation in Activity 1, task (ii)

The origami paper was used to explore the part-whole relationship between the isosceles triangle (the second triangle) and the initial square. $P$ tried many times to fold the paper in different ways, but she could not see the relationship. Then the teacher-researcher provided a hint: "Can you cut the square into two equivalent rectangles, and then see how the rectangle (half of the square) can cover the surface of the triangle?". P gave some thought to the suggestion, and two minutes later, $\mathrm{P}$ experimented with the idea to cut the rectangle diagonally into half to make two smaller right triangles. Hence, $P$ had four equivalent right triangles from a piece of origami paper or a square unit. Finally, $\mathrm{P}$ found that two smaller right triangles could fit in into the second triangle (the isosceles triangle). Based on her experimentation, $\mathrm{P}$ concluded that to cover the shaded area of the second triangle, $\mathrm{P}$ needed half of the square, which was equal to the first triangle (the isosceles right triangle) (Figure 8).

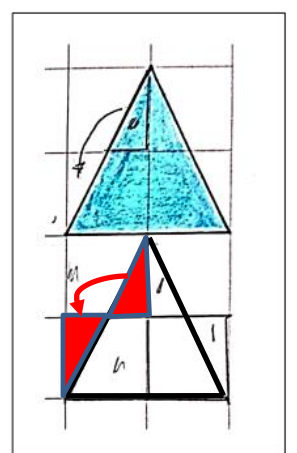

Figure 9. The compensation strategy (1)

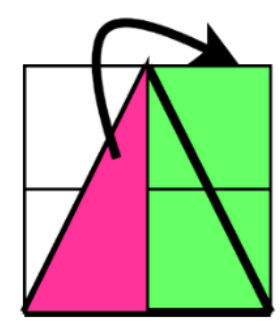

Figure 10. The compensation strategy (2)

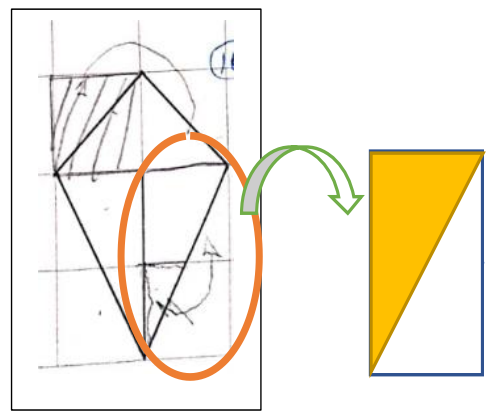

Figure 11. The absence of partwhole relationship in P's reasoning.

In Activity 1, task (iii), P seemed confident to use the compensation strategy to compare the area of all the three figures. For example, to compare the area of the isosceles triangle with the rectangle, $P$ cut the top half of the triangle and moved it into the empty space below to make a full square, and then she did the same for the other half on the right side (Figure 9). She concluded that the area of the isosceles triangle equals to the area of the rectangle. When performing the compensation, $P$ could only see one unit square as one whole that can be recomposed and decomposed, but $P$ did not see that two squares (a rectangle) could also mean one whole that can be recomposed and decomposed (Figure 10). In performing conservation activity by covering, there was no evidence that $\mathrm{P}$ used the part-whole relationship in comparing area of different shapes. 


\section{Activity 2. Area Conservation by Tessellation}

The experience with the area conservation by covering enabled $\mathrm{P}$ to abstract the concept of compensation in conserving areas. $P$ used the origami paper as a fixed unit to make an indirect comparison between area of different shapes. In Activity 2, the origami paper was no longer in use. P used the grid on the checkered paper as a representation of the origami paper. Various shapes were drawn on the checkered paper, and $P$ was challenged to examine which shapes have equal area. During the activity, $\mathrm{P}$ used the compensation strategy to all the sixteen shapes in determining the area in terms of unit square. $P$ could compare area of different shapes by performing compensation, but not the partwhole relationship. As an example, Figure 11 shows the process of moving the small triangle at the bottom of the kite to the empty upper part. P indicated by drawing a curved arrow showing the shifting and rotating movement of that partial part. $P$ did not recognize the part-whole relationship as indicated with the illustration, that is the right triangle is half of the rectangle. By looking at the rectangle as a whole and the triangle as half of the rectangle, $\mathrm{P}$ could have approached the problem by perceiving that the area of the triangle is half the area of the rectangle.

\section{Activity 3. Area Comparison}

Activities 3 and 2 were comparable, but the focus of Activity 3 was to compare areas of two shapes. There were four tasks in area comparison activity. In comparing area of the shapes, $\mathrm{P}$ used the word 'square' to indicate the area measurement of the shapes rather than use the letter ' $A$ ' as introduced earlier. The square was used consistently as the fixed unit to compare are of two shapes in all tasks. For example, the area of the parallelogram is six squares, and the area of the star is three squares, thus the area of the parallelogram is larger than the area of the star (task (iv), Figure 5). Although P could compare the magnitudes (in terms of area) by using area conservation concept, the idea of comparing magnitudes using the letter-symbol, $A$, did not emerge from the discussion.

Of the four tasks in area comparison activity, task (iii) was the most difficult for $P$ to solve. Initially $P$ thought that the shape on the left side is larger than the shape on the right side (the diamond shape) (Figure 12). Hence, a conversation took place between the teacher-researcher $(T)$ and $P$ to help $P$ look at the relationship between $\mathrm{T}(\mathrm{ii})^{*}$ and $\mathrm{T}(\mathrm{iii})^{* *}$.

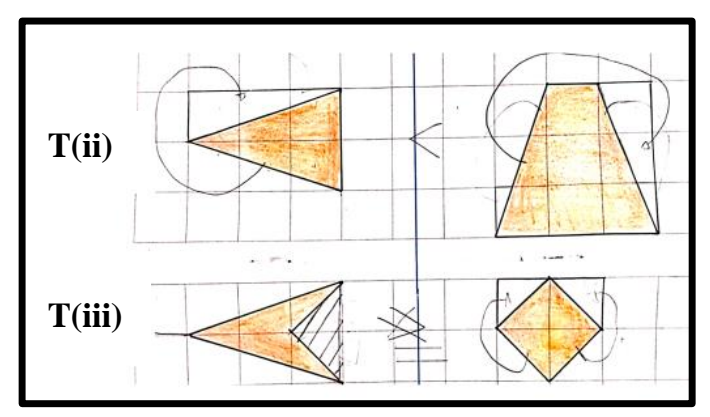

Figure 12. P's written response on Area Comparison Activity

${ }^{*} \mathrm{~T}$ (ii) $=$ The triangle in task (ii)

${ }^{* *} T($ iii) $=$ The triangle with notch in task(iii)

From the conversation (Transcription 1, line 6-8) and P's written response in task (ii), $P$ could find the area of $T$ (ii) easily by compensation. However, $P$ did not see the relation between $T$ (ii) and $T$ (iii). Thus, the teacher-researcher directed P's attention to the two shapes and gave a hint to look at the difference between $T$ (ii) and $T$ (iii) (Transcription 1, line 9). After noticing that the notch is another triangular 
shape with area equals to one square, $P$ concluded that the area of $T$ (iii) was two squares, and thus equals to the area of the diamond shape.

$P$ was very confident in performing the compensation strategy when she could recompose any two partial units to become a square. Other shapes with partial units that cannot be recomposed into one square were indicated as difficult problems. This kind of problem required $\mathrm{P}$ to see a bigger picture of the shapes and to see the part-whole relationship.

Transcription 1 (difficulties when the partial units cannot be recomposed into a unit square)

\begin{tabular}{|l|l|l|}
\hline 1 & $\mathrm{~T}$ & $\begin{array}{l}\text { "This [T(ii)] and this [T(iii)], which one } \\
\text { has a bigger area?" }\end{array}$ \\
\hline $\mathbf{2}$ & $\mathrm{P}$ & "This." [pointing to T(ii)] \\
\hline $\mathbf{3}$ & $\mathrm{T}$ & $\begin{array}{l}\text { "Can you see how much the } \\
\text { difference is, between this [T(iii)] } \\
\text { compared to this [T(ii)]? }\end{array}$ \\
\hline $\mathbf{4}$ & $\mathrm{P}$ & [silent, cannot answer] \\
\hline 5 & $\mathrm{~T}$ & "What was the area of this [T(ii)]?" \\
\hline 6 & $\mathrm{P}$ & "That was ... three." \\
\hline 7 & $\mathrm{~T}$ & "How did you know that it's three?" \\
\hline $\mathbf{8}$ & $\mathrm{P}$ & $\begin{array}{l}\text { "Because this part was moved here." } \\
\text { [pointing and indicating a compensation } \\
\text { as shown in T (ii)] }\end{array}$ \\
\hline $\mathbf{9}$ & $\mathrm{T}$ & $\begin{array}{l}\text { "Ok, so the difference between this } \\
\text { shape [T(iii)] and this shape [T(ii)] is } \\
\text { because there is a bit of notch. Can } \\
\text { you see how much the reduction is?" }\end{array}$ \\
\hline 10 & $\mathrm{P}$ & $\begin{array}{l}\text { [silent, and after about 50 seconds] } \\
\text { mmm... [pointing to the smaller triangle } \\
\text { in T(iii)] }\end{array}$ \\
\hline 11 & $\mathrm{~T}$ & "So, what shape is it?" \\
\hline 12 & $\mathrm{P}$ & "Mmm.. a triangle." \\
\hline 13 & $\mathrm{~T}$ & "What's the area of it?" \\
\hline 14 & $\mathrm{P}$ & Mmm... \\
\hline
\end{tabular}

\begin{tabular}{|l|l|l|}
\hline 15 & T & $\begin{array}{l}\text { "You can shade the notch part if you } \\
\text { want to know the area of that one." }\end{array}$ \\
\hline 16 & P & [able to shade the correct part from T(iii)] \\
\hline 17 & T & $\begin{array}{l}\text { "Now, have you seen the difference } \\
\text { between the this [T(iii)] and this [T (ii)]? }\end{array}$ \\
\hline 18 & P & "Yes, I have." \\
\hline 19 & T & "What is the difference?" \\
\hline 20 & P & "The notch." \\
\hline 21 & T & "How big is the notch?" \\
\hline 22 & P & "A triangle." \\
\hline 23 & T & "What's the area of the triangle?" \\
\hline 24 & P & "The area is ... one square." \\
\hline 25 & T & "How do you know it is one square?" \\
\hline 26 & P & $\begin{array}{l}\text { "Because this is moved here" } \\
\text { [indicating a compensation strategy]. }\end{array}$ \\
\hline 27 & T & $\begin{array}{l}\text { "Ok, so the area of the region in } \\
\text { orange is?" [the shading was in orange] }\end{array}$ \\
\hline 28 & P & "Two!" \\
\hline 29 & T & "How do you know it's two?" \\
\hline 30 & P & $\begin{array}{l}\text { "Because one square is subtracted } \\
\text { from three squares." }\end{array}$ \\
\hline
\end{tabular}

$$
\begin{aligned}
& T=\text { the teacher }- \text { researcher } \\
& P=\text { the pupil }
\end{aligned}
$$

\section{Activity 4. Letter- Symbolic Comparison}

Activity 4 was designed to foster P's thinking in comparing magnitudes of area when different units of measurement were employed. $P$ was expected to perceive the relation between magnitudes and on their variability by using letter-symbols. Figure 13 shows P's written responses to the worksheet. This worksheet was designed to investigate how $P$ perceived the relationship between two measurement units and the area of the shapes. There were four tasks in Activity 4 where $P$ had to compare the results of the area measurement of the same shape but with two different units of measurement. The new letter-symbol $B$ was introduced to represent the area of the isosceles right triangle (half of $A$ ). Figure 13 shows how $P$ demonstrated a good knowledge of fraction when identifying the area of the first shape as two and a half square units. Instead of writing the area measurement as $2 \frac{1}{2} A$, $\mathrm{P}$ wrote $2 \frac{1}{2}$ without the letter $A$ to indicate the area of the shape. To find out the area of the same shape with a different unit of measurement, $P$ drew the 'new' unit of measurement on the shape and found that there were five triangles $B$ covering the surface of the shape (Figure 13, task (i)). 
(i)

Tentukan Luas bangun datar berikut:

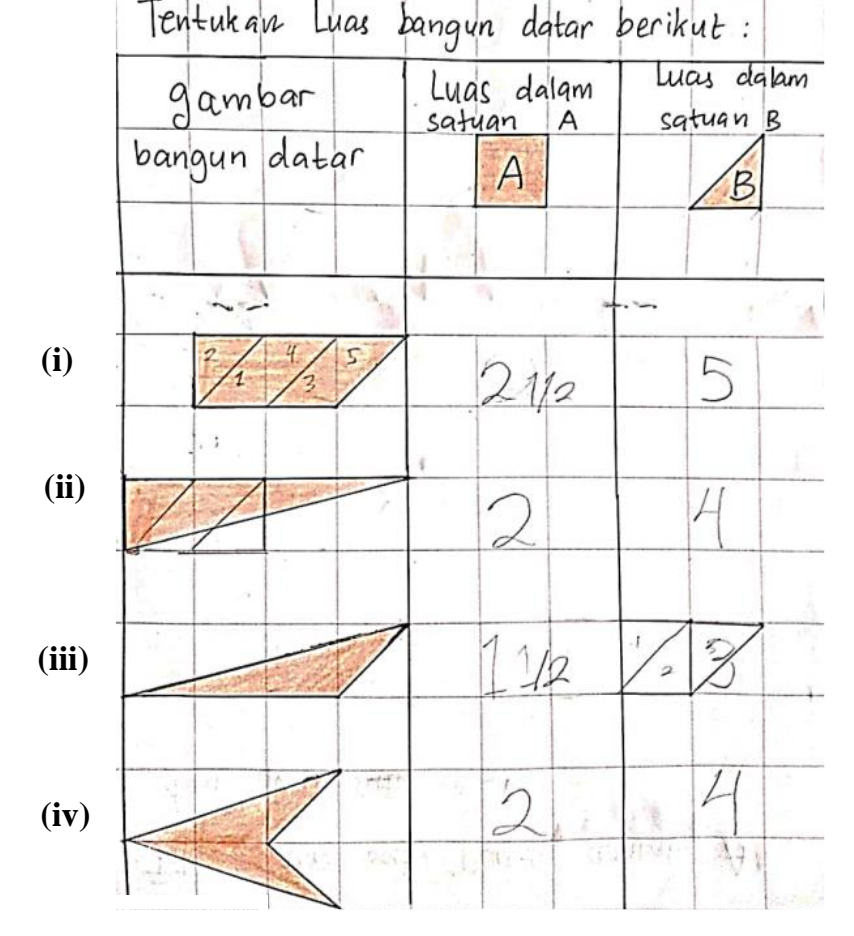

Figure 13. The quantitative relationship in terms of unit area $A$ and $B$

$P$ used the compensation strategy to find the area of in task (ii), i.e., the area of the right-triangle is equal to two squares. P's annotations showed how she partitioned the area of the squares across the diagonals and obtained four isosceles right triangles with area that equals to those of two squares. Up to this point, $\mathrm{P}$ had found the relationship between the area in terms of $B$ and the area in terms $A$, the area in $B$ is double the area in $A$. Thus, in determining the area of shapes 3 and $4, P$ did not show any annotations, suggesting that she was no longer partitioning the shapes, but she was looking at the number of squares and double the number to get the area in terms of $B$. Although she answered all questions in the worksheet correctly, her explanations during the discussion did not involve the lettersymbols of $A$, the area of a square, and $B$, the area of the right triangle. She was focusing on the number of squares or triangles, without associating the areas to the symbol representations, $A$ and $B$. Thus, the following discussion took place to encourage $\mathrm{P}$ to use the letter-symbols, $A$ and $B$ :

Transcription 2 (the relationship between 100A and 200B)

\begin{tabular}{|l|l|l|}
\hline 1 & T & "What is the area of this shape in terms of $A$ ?" (Shape 1, Figure 13) \\
\hline 2 & P & "Two and a half $A . "$ \\
\hline 3 & T & "What about this one?" (asking the area in terms of $B$ ) \\
\hline 4 & P & "Five B." \\
\hline 5 & T & "Why are they different?" \\
\hline 6 & P & "Because this is just half of the square." (pointing to the triangle) \\
\hline 7 & T & "Then?" \\
\hline 8 & P & "So, the number is greater." (meaning that five is more than two and a half) \\
\hline 9 & T & "Ok, what if I have a shape whose area is a hundred A? How many B is that?" \\
\hline 10 & P & (smiling, seems that she did not expect a big number) "a hundred $A$ is ... a thousand?" (doubt) \\
\hline 11 & T & (repeating the questions) "Now, you can imagine a hundred squares. If I measure the area of \\
& & a hundred squares with the triangle whose area is $B$, how many triangles are there?" \\
\hline 12 & P & "Fifty...?" (sounds unsure) \\
\hline
\end{tabular}




\begin{tabular}{|l|l|l|}
\hline 13 & T & "How did you get fifty?" \\
\hline 14 & P & "So, a hundred A" ... (thinking, pause) ... "How many B?" (asking to herself) \\
\hline 15 & T & $\begin{array}{l}\text { "Can you look at what you have been studying?" (The intention of asking this was to let her see } \\
\text { her own drawings of the squares and triangles and how they are related.) }\end{array}$ \\
\hline 16 & P & (after a while) "Two hundred" \\
\hline 17 & T & "How did you get that?" \\
\hline 18 & P & "I imagined one row of ten squares, then, since every square has two B, I multiply it by two." \\
\hline
\end{tabular}

Transcription 2 shows that $P$ noticed the relation between area and the different size of unit measurements, $A$ versus $B$. To determine whether she had developed a more general relationship between $A$ and $B$, the following question which involved a larger number was given: "What if I have a shape whose area is a hundred $A$, how many $B$ is that?" (Transcription 2, line 9). P's answer suggested that she did not immediately infer the relation between the square ' $A$ ' and the triangle ' $B$ ' when the numbers were big. The question was rephrased, this time by involving the terms squares and triangles: "Now, you can imagine a hundred squares. If I measure the area of a hundred squares with the triangle whose area is $B$, how many triangles are there?" (Transcription 2, line 11). P was able to answer the question correctly and provide a reasonable argument: "I imagined one row of ten squares, then, since every square has two B's, I multiply it by two" (Transcription 2, line 18). P's explanation shows that the drawing representation of squares and triangles has facilitated her reasoning in expressing the relationship between $A$ and $B$, although the relationship between $A$ and $B$ in terms of the symbolic representation has not been accomplished.

Further scaffolding was used to foster P's use of letters $A$ and $B$ to show the quantitative relationship between $A$ and $B$. $P$ was asked to find the area of a shape in terms of $A$ when the area equals to 130B. Transcription 3 (line 4) shows how $P$ counted by twenty to solve the problem, i.e., "twenty, forty, sixty, ...", by using fingers to keep track of her counting. However, $P$ did not realize that 130 was not a multiple of 20 , and hence $P$ made a mistake when she erroneously concluded that $130 \mathrm{~B}$ equals to $70 \mathrm{~A}$. Although she employed the relationship $20 B=10 A$ while counting, she did not immediately see the equivalence between $20 B=10 A$ and $10 B=5 A$.

Transcription 3 (the relationship between 130B and 65A)

\begin{tabular}{|l|l|l|}
\hline 1 & T & $\begin{array}{l}\text { "Now, I have a shape whose area is 130B. If you measure the shape with the square whose } \\
\text { area is A, how many squares are there?" }\end{array}$ \\
\hline 2 & P & $\begin{array}{l}\text { P responded by counting silently in her head, while sometimes raised her fingers indicating that she } \\
\text { was performing a mental calculation) } \\
\text { "Mmmm... seventy?" }\end{array}$ \\
\hline 3 & T & "Why seventy?" \\
\hline 4 & P & $\begin{array}{l}\text { "Because I used a similar way like the previous one, but I counted like this: twenty" (raising } \\
\text { one finger), "forty", (raising the second finger), "sixty" (raising the third finger), "eighty" (raising the } \\
\text { fourth finger), "a hundred" (raising the fifth finger), "a hundred and twenty" (raising the sixth } \\
\text { finger). "Since you asked for a hundred and thirty, then it becomes seventy." }\end{array}$ \\
\hline 5 & T & "Wait, how many that you need more?" \\
\hline 6 & P & "ten" \\
\hline 7 & T & $\begin{array}{l}\text { "Ok, can you repeat once again how you counted? And then write it down." } \\
\text { (I also ask her to articulate the B and A while counting) }\end{array}$ \\
\hline
\end{tabular}

After writing down the list of equations showed in Figure 14 (on the left side), $\mathrm{P}$ kept consistent with the first answer, that $130 \mathrm{~A}$ equals to $70 \mathrm{~B}$. Thus, the researcher asked $\mathrm{P}$ to draw the representation 
of ten $B$ (or ten squares) using triangles, $P$ came up with the drawing shown in Figure 14 (on the right side). When $P$ finished her drawing, she still did not see how her drawing could help her in solving the problem. However, after the question was repeated, $P$ took some time to think while looking at her drawing and finally she figured out that every ten triangles equal five squares, which means $10 B=5 A$, and she finally concluded $130 \mathrm{~B}$ equals to $65 \mathrm{~A}$.

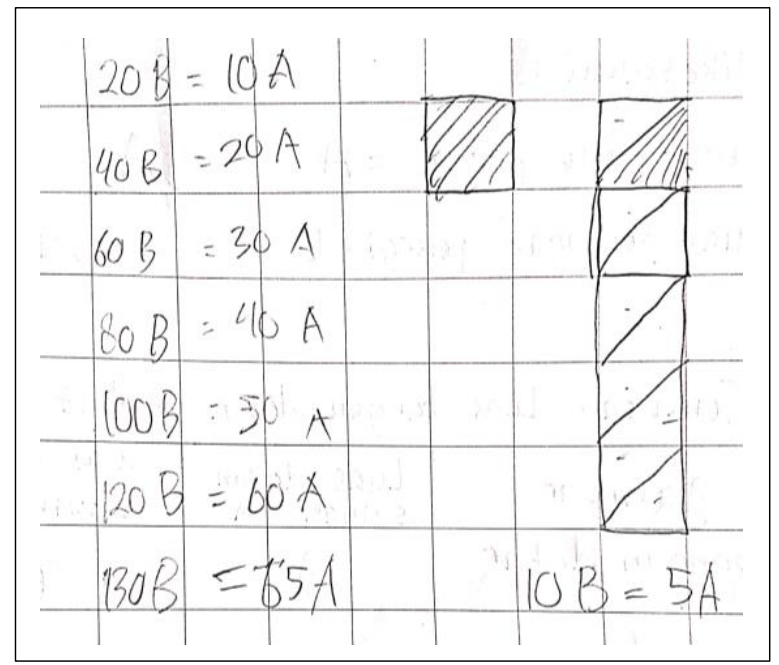

Figure 14. The quantitative relationships when partial units are different

In this example, although $\mathrm{P}$ could not see immediately the quantitative relationship between $A$ and $B$ in terms of symbolic representation, her diagram representation of squares and triangles finally helped her in drawing a conclusion that the area in terms of $B$ is double the area in terms of $A, A=2 B$ or $2 B=A$. Although the two equations: $2 B=A$ and $10 B=5 A$ are equivalent, $P$ did not see the equivalence. There was a transformation process between different representations of the same object. In this case, a transformation from a concrete situation that involves the diagram representation to a more abstract situation that involves the symbolic representation.

\section{Discussion}

The set of activities and the sequence of presentation was designed to promote pupils' thinking in developing the concept of quantitative relationships in early algebra through area conservation activities. In this study, there are two kinds of activities in comparing magnitudes in terms of area: first is conservation and comparison of area between two or more shapes (Activities 1 to 3 ); and second is the quantitative relationship between the results of measurement and the unit of measurement (Activity 4). While the first one is intended to develop the notion of quantitative relationship of 'equal', 'smaller than' and 'larger than', the second one is intended to develop the notion of quantitative relationship between the measurement unit and the result of measurement. All the activities were designed so that P could explore the four concepts of compensation, part-whole relationship, transitivity, and reversibility while conserving areas, without knowing the measurement of the shapes and unit measurements.

At the start of the activities, the letter $A$ was introduced to signify the area of a unit square on the whiteboard (modelled by a piece of origami paper) to compare the area of different shapes, yet $\mathrm{P}$ did not reason in terms of $A$ during Activities 1 to 4 . That $P$ did not make use of the letter-symbol in her reasoning could be due to the regularity of the shapes and the presence of the countable unit squares on the whiteboard and on the checkered paper exercise book. Although the letter-symbol was not employed in P's reasoning during the area conservation activity, the notion of quantitative relationship in comparing 
magnitudes was present. This is in line with Kieran (2004) statement that early algebraic thinking does not necessarily involve letter-symbols.

In accordance with Davydov's $(1962 ; 1975)$ studies regarding reversibility and transitivity as the property of equality and/or inequality relationships, this study found evidence that P's reasoning involved the concepts of reversibility and transitivity when comparing the area between a parallelogram and a triangle during the area conservation activity (Activity 1, task (i), Figure 7). However, unlike Davydov's experiments that used letters to represent the magnitudes of objects being compared, this study used a letter to represent another object as a point of reference, or a fixed unit, in comparing area magnitudes of different objects. Therefore, there is a substantial difference between the present study and Davydov's studies. In Davydov, pupils made direct comparison of magnitudes between two objects, followed by exploring how to preserve and disturb equality of two magnitudes to come to the concepts of addition and subtraction and their properties. Whereas in the present study, the comparison was an indirect comparison as another object, a unit square, was used as a point of reference. For example, a transitive reasoning in constituting an indirect comparison: "the area of the parallelogram is six squares, and the area of the star is three squares, thus the area of the parallelogram is larger than the area of the star" (Activity 3, task (iv)).

Piaget's (1960) conservation tasks were also adapted in the CSMS (Concepts in Secondary Mathematics and Science) research project to investigate pupils' levels of understanding in the measurement concept (Hart, 1981). The findings indicated that the area conservation tasks were relatively easy when the shapes can be decomposed into several whole and half squares, but the levels of difficulty increased when the shapes cannot be decomposed into whole and half squares (Hart, 1981). This is in line with the findings of the present study, when P dealt with the T(iii) problem (Activity 3 , task 3). Based on our analysis, pupils need to see the relationship between two shapes, e.g., the concave-convex polygon relationship (T(ii) and T(iii)), and not only the triangle-rectangle relationship as it was suggested by Hart (1981). The level of difficulty in the 'different unit of measurement' problem was even higher, since most of the participants in Hart's (1981) study responded that the area with a $1 / 2 \mathrm{~cm}$ unit square was double the area with $1 \mathrm{~cm}$ unit square. Therefore, besides the area conservation concept, understanding how the result of measurement depends on the size of the unit measurement is also a fundamental concept in area measurement.

Kamii and Kysh (2006) has pointed out that knowing the formula 'length $\mathrm{x}$ width' does not indicate the understanding of the area measurement concept. Outhred and Mitchelmore (2000) suggested that the area measurement concept should be introduced to pupils as a matter of covering a region with a fixed unit, for example a unit square. Thus, the area conservation activity proposed in this study could compel pupils' attention to focus on covering a region and perceiving a unit square as the unit of iteration in area measurement, which was not self-evident for pupils.

This study found that $P$ used the compensation strategy in almost all tasks from Activities 1 to 4 , but the idea of part-whole relationship was absent. The compensation strategy or the 'cut - move - paste' in the area conservation activity was also reported in Kordaki (2003) and Ekawati et al. (2019). It is worth noting that the part-whole relationship, or analyzing parts that together form a whole was highlighted by $\mathrm{Ng}$ (2004) as one of the fundamental thinking processes in developing pupils' algebraic thinking. Hence, further investigation is necessary to design activities that can invite pupils' reasoning related to part-whole relationship while engaging in the area conservation activity.

The pupil participating in this study could see how different units of measurement can produce different area measurements. As soon as $P$ could perceive that in every square $(A)$ there was two 
triangles $(B)$, she was able to conclude that the area in terms of $B$ was twice as the area in terms of $A$ (see the example in Transcription 2). However, $P$ was challenged when asked to express the area in terms of $A$ when the area in terms of $B$ was given (see the example in Transcription 3). To overcome this difficulty, $\mathrm{P}$ needed to go back to the diagram representation of the squares and triangles to conclude that $10 B=5 A$. It is important to note that although $P$ has acquired the relationship $20 B=10 A$, this learning does not transfer to related equivalence such as $10 B=5 A$ from $20 B=10 A$. There are two different types of representations in which $\mathrm{P}$ had to transform back and forth between the diagram representation of squares and triangles and the symbolic representation in terms of $A$ and $B$. The issue of transformation of different representations in pupils' mathematical activities was elaborated further by Duval (2017), in which he argued that the transformation of semiotic representations is at the heart of the mathematical way of working. Hence, understanding pupils' cognitive process to move from a concrete (diagram) representation to a more abstract (symbolic) representation, and analyzing different kinds of transformations require further investigations.

\section{CONCLUSION}

The pupil started developing fundamental ideas in conserving areas as the mathematical activities involved the comparing of magnitudes of area. The concrete materials and the geometrical representations were found to be useful in fostering the pupil's thinking, with each subsequent activity challenging the pupil to a higher level of the concepts related to area of geometrical figures. Concepts of reversibility, compensation, and transitivity seemed to evolve naturally from engaging with the activities, but this was not the case for the part-whole relationship. Although the letter-symbol was not employed in the pupil's reasoning during the area conservation activity, the notion of quantitative relationship in comparing magnitudes was present. The changing of the unit measurement allowed the pupil to see how it affects the result of measurement, and then exploring the quantitative relationship.

This study suggests that the concept of quantitative relationship can be explored together with the concept of area conservation in area measurement, that must precede the introduction to area formulae. Early introduction to formulae does not aid in acquiring the more fundamental concepts related to measurement. Pupils may be able to regurgitate formulae but their knowledge of fundamental concepts such as of conservation, part-whole relationship, reversibility, and transitivity may be questionable. Hence, such concepts need to be taught with good set of tasks.

We acknowledge that this study was conducted in a short period of time with only one pupil as the participant. However, we expect that the result of this study can provide insight and motivation for further study in understanding the relationship between the concept of quantitative relationship in early algebra and the concept of area conservation in geometry. Further study in which the designed activities can be enacted in a real classroom setting is also needed to analyse how pupils develop their understanding in the frame of sociocultural perspective.

\section{Acknowledgments}

This paper was supported by LPDP (Lembaga Pengelola Dana Pendidikan), the Ministry of Finance of Indonesia. 


\section{Declarations}

Author Contribution

: PS: Conceptualization, Writing - Original Draft, Editing, Visualization, Formal analysis, and Methodology.

NSF: Conceptualization, Writing - Review \& Editing, Validation, and Supervision.

Funding Statement : This paper was supported by LPDP (Lembaga Pengelola Dana Pendidikan), the Ministry of Finance of Indonesia.

Conflict of Interest $\quad$ : The authors declare no conflict of interest.

Additional Information : Additional information is available for this paper.

\section{REFERENCES}

Amerom, B. A. V. (2003). Focusing on informal strategies when linking arithmetic to early algebra. $\begin{array}{llll}\text { Educational Studies in } & \text { 63-75. }\end{array}$ https://doi.org/10.1023/B:EDUC.0000005237.72281.bf

Banerjee, R., \& Subramaniam, K. (2012). Evolution of a teaching approach for beginning algebra. Educational Studies in Mathematics, 80(3), 351 - 367. https://doi.org/10.1007/s10649-011-9353-

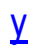

Baroody, A. J. (2003). The Development of Adaptive Expertise and Flexibility: The Integration of Conceptual and Procedural Knowledge. In A. J. Baroody \& A. Dowker (Eds.), The Development of Arithmetic Concepts and Skills: Constructive Adaptive Expertise. Routledge Ltd.

Blanton, M., Stroud, R., Stephens, A., Gardiner, A. M., Stylianou, D. A., Knuth, E., Isler-Baykal, I., \& Strachota, S. (2019). Does Early Algebra Matter? The Effectiveness of an Early Algebra Intervention in Grades 3 to 5. American Educational Research Journal, 56(5), 1930-1972. https://doi.org/10.3102/0002831219832301

Cobb, P., Confrey, J., diSessa, A., Lehrer, R., \& Schauble, L. (2003). Design experiments in educational research. Educational Researcher, 32 (1)(The role of design in educational research), 9-13. https://doi.org/10.3102/0013189X032001009

Davydov, V. V. (1962). An Experiment in Introducing Elements of Algebra in Elementary School. Soviet Education, 5(1), 27-37. https://doi.org/10.2753/res1060-9393050127

Davydov, V. V. (1975). The psychological characteristics of the "prenumerical" period of mathematics instruction. In L. P. Steffe (Ed.), Children's capacity for learning mathematics. Soviet studies in the psychology of learning and teaching mathematics (Vol. 7, pp. 109-205). Chicago: University of Chicago.

Dougherty, B. (2008). Measure Up: A Quantitative View of Early Algebra. In J. J. Kaput, D. W. Carraher, \& M. L. Blanton (Eds.), Algebra in the Early Grades (pp. 389-412). Routledge.

Duval, R. (2017). Understanding the Mathematical Way of Thinking - The Registers of Semiotic Representations. Springer International Publishing : Imprint: Springer.

Ekawati, R., Kohar, A. W., Imah, E. M., Amin, S. M., \& Fiangga, S. (2019). Students' cognitive processes in solving problem related to the concept of area conservation. Journal on Mathematics Education, 10(1), 21-36. https://doi.org/10.22342//me.10.1.6339.21-36 
Freiman, V., \& Fellus, O. O. (2021). Closing the gap on the map: Davydov's contribution to current early algebra discourse in light of the 1960s Soviet debates over word-problem solving. Educational Studies in Mathematics, 106(3), 343-361. https://doi.org/10.1007/s10649-020-09989-6

Freudenthal, H. (1974). Soviet Research on Teaching Algebra at the Lower Grades of the Elementary School. Educational Studies in Mathematics, 5(4), 391-412. https://doi.org/10.1007/BF00684710

Freudenthal, H. (1978). Weeding and sowing: Preface to a science of mathematical education. Dordrecht, the Netherlands: Reidel.

Hart, K. (1981). Measurement. In K. M. Hart (Ed.), Children's understanding of mathematics (Vol. 9-22).

Kamii, C., \& Kysh, J. (2006). The difficulty of "length×width": Is a square the unit of measurement? The Journal of Mathematical Behavior, 25(2), 105-115. https://doi.org/10.1016/i.jmathb.2006.02.001

Kaput, J. J. (2008). What is Algebra? What is Algebraic Reasoning? In J. J. Kaput, D. W. Carraher, \& M. L. Blanton (Eds.), Algebra in the Early Grades (pp. 5-17). Routledge.

Kieran, C. (2004). Algebraic thinking in the early grades: What is it. The Mathematics Educator, 8(1), 139151.

Kieran, C., \& Ng, S. F. (2018). Teaching and learning algebraic thinking with 5- to 12-year-olds [electronic resource] : the global evolution of an emerging field of research and practice / Carolyn Kieran, editor. Springer International Publishing.

Kieran, C., Pang, J., Schifter, D., \& Ng, S. F. (2016). Early Algebra: Research into its Nature, its Learning, its Teaching. Springer Open. https://doi.org/10.1007/978-3-319-32258-2

Kordaki, M. (2003). The Effect of Tools of a Computer Microworld on Students' Strategies regarding the Concept of Conservation of Area. Educational Studies in Mathematics, 52(2), 177-209. https://doi.org/10.1023/A:1024065107302

Kospentaris, G., Spyrou, P., \& Lappas, D. (2011). Exploring students' strategies in area conservation geometrical tasks. Educational Studies in Mathematics, 77(1), 105-127. https://doi.org/10.1007/s10649-011-9303-8

Lehrer, R. (2003). Developing Understanding of Measurement. In J. Kilpatrick, W. G. Martin, \& D. Schifter (Eds.), A research companion to principles and standards for school mathematics (pp. 179-192). Reston, VA : National Council of Teachers of Mathematics.

NCTM. (2000). Principles and standards for school mathematics. The National Council of Teachers of Mathematics, Inc.

$\mathrm{Ng}, \mathrm{S}$. F. (2004). Developing algebraic thinking in early grades: case study of the Singapore primary mathematics curriculum. The Mathematics Educator, 8(1), 39-59.

OECD. (2019). PISA 2018 assessment and analytical framework. https://doi.org/10.1787/b25efab8-en

Outhred, L. N., \& Mitchelmore, M. C. (2000). Young Children's Intuitive Understanding of Rectangular Area Measurement. Journal for Research in Mathematics Education, 31(2), 144-167. https://doi.org/10.2307/749749

Peck, D. M., \& Jenks, S. M. (1988). Reality, Arithmetic, Algebra. Journal of Mathematical Behavior, 7, 8591.

Piaget, J., Inhelder, B., \& Szeminska, A. (1960). The child's conception of geometry (E. A. Lunzer, Trans.). Routledge and Kegan Paul. 
Skemp, R. R. (1976). Relational Understanding and Instrumental Understanding. Mathematics Teacher, 77, 20-26. https://doi.org/10.5951/AT.26.3.0009

Steffe, L. P., \& Thompson, P. W. (2000). Teaching experiment methodology: Underlying principles and essential elements. In R. Lesh \& A. E. Kelly (Eds.), Research design in mathematics and science education (pp. 267-307). Hillsdale, NJ: Erlbaum.

Stephan, M., \& Clements, D. H. (2004). Linear and Area Measurement in Prekindergarten to Grade 2. In D. H. Clements (Ed.), Learning and Teaching Measurement (2003 Yearbook) (pp. 3-16). National Council of Teachers of Mathematics: Reston, VA.

Usiskin, Z. (1988). Conceptions of School Algebra and Uses of Variables. In A. F. Coxford \& A. P. Shulbert (Eds.), The Ideas of Algebra, K-12. 1988 Yearbook. National Council of Teachers of Mathematics.

Wertheimer, M. (1945). Productive thinking. New York: Harper \& Brothers. 
() 